\title{
Analysis of the changes and difficulties arising from kidney transplantation: a qualitative study ${ }^{1}$
}

\author{
Daniela Cristina Sampaio de Brito ${ }^{2}$ \\ Alessandra Moregola de Paula ${ }^{3}$ \\ Fabiane Rossi dos Santos Grincenkov ${ }^{4}$ \\ Giancarlo Lucchetti ${ }^{5}$ \\ Hélady Sanders-Pinheiro ${ }^{6}$
}

\begin{abstract}
Objective: to identify the main gains and stressors perceived by the patient, one year subsequent to kidney transplantation. Method: a qualitative study, in which the data were obtained and analyzed through the Discourse of the Collective Subject and frequency counting, with the participation of 50 patients who had received kidney transplantation. Results: the sample presented a mean age of $44 \pm 12.8$ years old, and a predominance of males (62\%). The principal positive changes provided by the transplant were: return to activities; freedom/independence; well-being and health; strengthening of the I; and closening of interpersonal relationships. The most-cited stressors were: fear; medication; excess of care/control; specific characteristics of the treatment; and failure to return to the social roles. Conclusion: kidney transplantation caused various positive changes in the patient's routine, with the return to activities of daily living being the most important gain, in the participants' opinion. In relation to the stressors, fear related to loss of the graft, and questions relating to the immunosuppressive medication were the main challenges to be faced following transplantation.
\end{abstract}

Descriptors: Kidney Transplantation; Quality of Life; Stress, Psychological; Qualitative Research.

\footnotetext{
${ }^{1}$ Paper extracted from master's thesis "Relation between stress and coping patterns and medication adherence in kidney transplantation", presented to Universidade Federal de Juiz de Fora, Juiz de Fora, MG, Brazil.

2 MSc, Psychologist, Hospital Público Regional de Betim, Betim, MG, Brazil. Professor, Centro Universitário UNA Belo Horizonte, Belo Horizonte, MG, Brazil.

3 Psychologist, Clínica na Prevent Senior Private Operadora de Saude, São Paulo, SP, Brazil.

${ }^{4}$ PhD, Professor, Faculdade de Psicologia, Centro de Ensino Superior de Juiz de Fora, Juiz de Fora, MG, Brazil.

${ }^{5}$ PhD, Professor, Faculdade de Medicina, Universidade Federal de Juiz de Fora, Juiz de Fora, MG, Brazil.

${ }^{6}$ PhD, Associate Professor, Faculdade de Medicina, Universidade Federal de Juiz de Fora, Juiz de Fora, MG, Brazil.
}

Corresponding Author:

Daniela Cristina Sampaio de Brito

Rua Camapuã, 930

Bairro: Grajaú

CEP: 30431-236, Belo Horizonte, MG, Brasil

E-mail: danielacbrito@hotmail.com
Copyright (c) 2015 Revista Latino-Americana de Enfermagem This is an Open Access article distributed under the terms of the Creative Commons Attribution Non-Commercial License (CC BY-NC).

This license lets others distribute, remix, tweak, and build upon your work non-commercially, and although their new works must also acknowledge you and be non-commercial, they don't have to license their derivative works on the same terms. 


\section{Introduction}

Chronic kidney disease (CKD) is currently a global public health issue ${ }^{(1)}$. In Brazil, according to the 2012 Census $^{(2)}$, the estimated total number of patients in the terminal phase of the disease is approximately 97,000, with a growing annual incidence.

The various treatments available for CKD - hemodialysis, peritoneal dialysis and kidney transplantation (KTx) - are not considered curative, but substitutive. Compared with the others, KTx is described as the best therapy for patients with terminal CKD, as it promotes better quality of life and lower mortality, as well as being associated with various benefits, such as reduction of healthcare costs ${ }^{(3)}$.

In spite of the numerous advantages arising from this procedure, transplant recipients face various challenges related to the new clinical condition ${ }^{(4)}$. The treatment following KTx encompasses many recommendations, such as: continuous use of immunosuppressive medication, prevention of infections resulting from decline in immunological function, regular clinical visits, advice on diet, and continuous physical activity(3).

In addition to the complexity of the treatment regimen, the patient must correctly follow the treatment proposed. Nonadherence to the immunosuppressive medication becomes a behavior of risk for the efficacy of the KTx, as minimal reductions in the dose, or simply forgetting to take it, can entail irreversible damage to the functioning of the graft ${ }^{(5-6)}$. As a result, subsequent to the KTx, the patient is subject to various worries, mainly related to feelings of fear and uncertainty regarding the survival of the graft, an aspect influenced directly by episodes of rejection and infections ${ }^{(7-8)}$.

In this context, living with the side effects of, and constant changes in, the dosages of the medications ${ }^{(9)}$; the social pressure for returning to the routine held prior to the disease, given that the KTx does not change the chronic status, as it does not lead to a cure of the CKD (10); difficulties entering the job market; the reduction in monthly income(11); and constant monitoring from family members, the live donor and the patient herself, in the light of the necessity of strict care ${ }^{(12)}$, can also have negative repercussions in the life of the transplant recipient.

Indeed, various quantitative studies have shown that KTx does not eliminate the stress associated with health/illness ${ }^{(8,11,13-14)}$, although a few qualitative studies have assessed this relation ${ }^{(15)}$. When the descriptive aspects and personal perceptions are valorized, the private becomes the focus of the social totality, seeking not only to understand the subjects involved, but, through their intermediation, to understand the general context $^{(16)}$. As a result, the proposal for this study is to understand the experience of living with the graft and its challenges, based on the perspective of the patients who undergo KTx. It is believed that this knowledge can help in the search for interventions which are more suited to the actual needs of this clientele, impacting positively on the adjustment to the demands posed by the treatment.

\section{Objective}

To identify the principal gains and stressors perceived by the transplant recipients, subsequent to KTx.

\section{Material and Method}

This qualitative study was undertaken with transplant recipients monitored in a Brazilian university medical center, located in the city of Juiz de Fora, in the state of Minas Gerais, between August and December 2010. A sample size of 50 patients was adopted, invited consecutively by the researchers, based in previous studies of the qualitative methodology ${ }^{(17)}$. For inclusion in the study, the following criteria were adopted: minimum age of 18 years old, to be monitored in the service, and to have undergone KTx at least one year previously. Patients who had undergone re-transplantation and those who declined to participate in the research were excluded. The study was approved by the Research Ethics Committee of the Federal University of Juiz de Fora (0028/2010).

The exclusive selection of patients who had undergone KTx more than one year previously is related to the greater clinical stability and perceptive capacity regarding the impacts entailed by the treatment. The patients who had received transplantation less than one year previously are in the process of constant changes in the medication regimen, as they present a greater risk of acute rejection(18). In addition to this, these patients are in a state of great satisfaction, due to having succeeded in receiving $\mathrm{KTX}$, which therefore influences their evaluation regarding the many issues involved in the treatment ${ }^{(7,11)}$.

In this study, the decision was made to use the semistructured interview as the data collection instrument; it is made up of open and closed questions, divided in two sections. The first is referent to the patients' clinical and sociodemographic data, and the 
second is made up of two questions: 1) What are the main positive changes following KTx? and 2) What are the principal difficulties faced following KTx? The interviews were led by the service's psychologist, previously trained, and the data were collected only using this tool.

The patients were invited to participate in the study during their appearance at a routine consultation for monitoring following the KTx. Those who accepted to participate received information regarding the study and signed the terms of free and informed consent. The interview was held on the same day of the consultation and in single and individual sessions. The duration of the interviews, although varying according to each participant's discourse, was approximately one hour. The responses were recorded on an electronic device and subsequently transcribed and analyzed using the Discourse of the Collective Subject approach(19). For this analysis, no complementary instrument or specific software was used. The theoretical basis for comprehending the categories was the socio-historical approach, which aims for reflection on the individual in her totality, understanding her based on the units of mind, body and the social, inserting her in the participation of the production of the historical and cultural process ${ }^{(16)}$.

The choice of the Discourse of the Collective Subject as the methodological proposal allows a clearer interpretation of a specific social representation, as well as identifying the individuals' real thoughts, beliefs and feelings. For this, the following methodological figures are sought in the analysis of the verbal material: the Key Expressions (KE) and the Central Ideas (CI) for the constitution of the Discourse of the Collective Subject (DCS). The CI bring the essence of the discourse emitted by the individual, and the KE are literal transcriptions of part of the accounts, which provide the essence of the discoursive content. The DCS is constituted based on categories which represent the accounts and make them equivalent, as they express the same idea, represented by the category.

After this stage, the frequency count was undertaken. The qualitative data can also be understood quantitatively, without their complexity being impaired. In this case, the analysis seeks only to describe behaviors, not providing explanations which may infer theories or models(20)

\section{Results}

The sample's mean age was $44 \pm 12.8$ years old, $62 \%$ of the participants being male, and $70 \%$ stating that they were in a stable relationship. Only $26 \%$ of the patients lived in the city of Juiz de Fora. In relation to educational level, $52 \%$ had completed primary education, while of the others, $20 \%$ had completed senior high school, and $28 \%$, higher education. The majority (94\%) received the graft from a live donor and the median time since the KTx was 71.8 months (minimum: 12.00 - maximum: 230.00).

Five CI were identified for each question. The positive changes provided by the KTx were: return to activities (82\%); freedom/independence (72\%); wellbeing and health (66\%); strengthening of the I (52\%); and closening of the interpersonal relations (30\%). Fear $(66 \%)$ and questions relating to the medication (66\%) were the most cited stressors, followed by excess of care/control $(62 \%)$, specific characteristics of the KTx treatment (44\%) and non-return to social roles (24\%). The categories and subcategories referent to the principal positive changes subsequent to $\mathrm{KTx}$, based on the first question proposed, will be provided below.

Return to activities (CI-1) was described as the main gain perceived by the patients, following the undertaking of the KTx. This includes social, physical, leisure and occupational activities (whether linked or not to the production of income). The obligation to attend three times weekly in the dialysis center becomes an obstacle for arranging trips and days out, limiting social performance. Before the transplant, I had a very controlled life, you know? For example, if I wanted to go on a trip, I couldn't do it, unless the place where I was going had a hemodialysis treatment center. And the fact of you having to be doing hemodialysis one day yes, one day no - all that is very exhausting. And after every dialysis session, the person leaves as an absolute wreck! So, after the transplant, I have a life which is much closer to what is normal, you know! You can go somewhere without being worried... So the positive side of the transplant is being able to return to a normal life. (E45)

Besides the issue of time, the physical or psychological disposition also has a negative impact on the patient's functional capacity, even if there are no actual losses, or apparent disabilities. The transplant puts you in a much better physical situation than when you are doing hemodialysis. Before, I used to be quieter, I stayed at home more, I didn't go out... I didn't do anything. Now, I am more willing to do things, more active. (E46)

The second most-frequent central idea (CI-2) was freedom or independence. This perception of greater freedom or independence following the KTx was associated with issues of the dialysis treatment, a form of therapy which requires greater restrictions. 
Not attending the dialysis sessions, and not rigorously controlling the ingestion of food, were the aspects with the most relevance. Just not having to go back to that machine, it is everything! I will do anything so that I don't lose my kidney, because I'm not going back to that machine. (E10)

For some participants, no longer being 'tied' to the hemodialysis machine represented a greater feeling regarding independence; for others, it was related to the return of autonomy, both in relation to care for one's health and to the daily routine. What I couldn't do before, that I wanted to do - something so simple - but that I find extraordinary - is drinking water. Before the hemodialysis, normally I was very hungry, and I eat well already, and I would have lunch, and that crazy desire to drink water would come, and I would think: calm down, you can't drink water, you've got to drink just a little bit. So it came in that little bottle, nice and cold, cold water or juice, and I would take a little sip, it was frustrating. Today, that's not the case, I drink the water just like that, even from the bottle, like that, it's not hygienic, but it is a pleasure, it's such a simple thing, giving pleasure to us... (E18)

The category of well-being and health (CI-3) was related both to physical health (reduction of comorbidities and pain, and achieving appropriate clinical parameters) and to emotional health. The improvement in health in general allowed a feeling of greater well-being, directly influencing the undertaking of other activities and social roles. Before the transplant, I didn't do anything, because I didn't the energy for anything, you know. It is different now, I understand that I can do any little thing at home. I help my wife, I work a little. I help out in a football school, I do basic exercise, I run around the field... I do various things! (E21)

The strengthening of the I (CI-4) was related to self-esteem, self efficacy and vitality. Following the KTx, the patients mentioned positive changes in their body image and ability to cope with problems. The presence of more energy or disposition, also associated with the improvement in the state of health, contributed to a stronger perception of the I. I came to care more for myself. Before, I didn't bother to take care of my hair, all these things. I thought nobody would want to look at me because of the hemodialysis. Now I have begun a relationship... Yup, I am taking better care of myself. I even get compliments! Everything goes up - the person's self-esteem... Yes, it has improved... a lot! (E37)

Although less frequent, the category of closening of interpersonal relations (CI5) was observed by some of the interviewees. The conjugal/family bonds presented a transformation in the quality and intensity in the relationships. In the hemodialysis, you don't have to withdraw from your family... But with the transplant, you have more time to dedicate yourself to it. (E9)
In relation to the difficulties and obstacles faced following $\mathrm{KTx}$, the responses given by the patients are individualized below.

In this series, the feeling of fear was the aspect cited most (CI-1), and was related to the possible failure of the transplant in general. Now, one of the things about the transplant which leaves me worried is the rejection. The problem is that you have to take care of your immunity, which is very low... Because of this, you have to take greater care. For example, a different type of cold... I am very scared of this part, of rejection. I get terrified, and then I go and start thinking all sorts of rubbish. If you were to tell me that I have to go back to hemodialysis... (E35)

Episodes such as infection/admission to hospital, loss of the graft and needing to return to dialysis were much cited as causes of fear. I try not to think about it, but I end up doing just that. I had a urinary infection, I still do... And I get the feeling of ice in my stomach, that feeling always hits me. I have already talked with the doctor about this, and asked about the duration of the kidney, a transplant. Scared? Indeed I am. (E2)

Regarding the medication ( $\mathrm{CI}-2)$, the second most frequent, the uninterrupted use of the doses, and the rigorous arrangement of times were issues with a major load of stress. However, the side effects - in relation to immunosuppression - entailed a greater negative impact, both on the patient's well-being and on her daily routine. I went through a stressful situation with the medication: I became diabetic. (E32)

In the light of the need for correct adherence to the medication regimen, the difficulty in obtaining the medications in the public health service was indicated as a risk factor for the survival of the graft, and, consequently, as a concern for some patients. It hasn't actually run out, but it has been late in coming. (E40)

The excess of care/control (CI-3) was presented as the third most-cited subcategory, and as a major limit on activities. Patients avoided undertaking specific tasks or did not undertake certain behaviors, as a result of the belief regarding preserving the graft. This conduct, often, was considered a factor for stress, when it was seen as excessive and/or as monitored by third parties. My mother has always been very controlling, she has always enjoyed holding the reins. However, after the transplant it got worse! She is always on at me: you've got to take this, you've got to go there, you've got to do the test... She thinks I am doing every little thing wrong, she is always stopping me! (E45)

The treatment of the KTx (CI-4) includes various requirements, such as attending consultations regularly in the transplant outpatient center. This aspect was 
described as a stressor, especially for patients who do not live in Juiz de Fora, the city where the monitoring takes place. Some even lose an entire day in order to be in the health unit, as they live in distant cities or in other states. The issue is the treatment. Not that this is a burden, a weight, but you have to dedicate yourself to the treatment. You have to take time off, you have to do examinations, you have to go to the doctor, you have to get medication... At the end of the day, you do what has to be done, and sometimes this gets in the way a little. (E18)

Still on the subject of the KTx treatment, waiting for the clinical results of the regular examinations was experienced with great tension, as the results evaluate the state of the graft and the current situation of the KTx. The relationship with the health team or with the live donor was not considered a stressor by the majority of the interviewees. When existent, it was restricted only to the issue of the quality of the communication, or what was expected of the recipient following the donation, principally by the family or the donor: If I could yank it out, cut the kidney out with a knife and hand it back to him... (E37)

Finally, the category of social roles (CI-5) was mentioned a little in the discourse of this sample. Few patients felt that other people expected them to return to the activities interrupted by the diagnosis of CKD. However, the opposite was depicted with constancy, with the presence of social stigma - possibly associated with society's poor understanding regarding transplantation in general - being the main challenge to performance of the social role. Sometimes, people look at me like: that guy's handicapped, isn't he? Poor thing! (E30)

Non-return to work, and the financial impact, were equally influenced by stigmas still found by the transplant recipients, in relation to the opportunities offered on the job market. There are certain jobs that I can't get, because people are scared of giving a job to us. Any company, whenever you do a health test, rejects you. They just don't accept you! So you have to spend your whole life doing casual work. (E11)

Many of these restrictions, however, are put in place by the patient herself, in relation to tasks which, in her assessment, are considered risky or detrimental to the survival of the graft.

\section{Discussion}

The present study evaluated a population of young individuals, predominantly male, and who had received kidney transplants from live donors. These characteristics are similar to the population of kidney transplant recipients in Brazil. The median time which had passed since transplantation was greater than five years, evidencing that the interviewees had a considerable length of experience of life following the undertaking of the KTx.

In relation to the reports described by this study's patients, a series of positive changes achieved following the undertaking of the KTx were identified. In the participants' opinion, the most important gain was returning to activities. As CKD progresses, the patient presents symptoms which negatively interfere in her capacity to undertake day-to-day tasks ${ }^{(21)}$. If the patient is undergoing dialysis, she also faces a range of restrictions, from the clinical condition through to the time set aside for the treatment. As a result, routine activities - principally social/leisure activities (such as trips, days out and parties) are limited, making routine life monotonous and restricted ${ }^{(22)}$. The obligatoriness of attending the hemodialysis center three times per week or changing the peritoneal dialysis infusion bags four times a day also hinders the employment link.

In addition to returning to a more active routine, the lower impositions of treatment of the KTx also contribute to a greater perception of freedom or independence ${ }^{(12)}$, as evidenced by the present study. This gain brings extensive consequences for the life of the transplant recipient, ranging from returning to activities interrupted when they fell ill(4), to the feeling of greater autonomy. The fact of no longer depending on the machine, or of being able to enjoy simple pleasures such as drinking and eating with fewer restrictions, promotes social participation and strengthens self esteem and self-efficacy.

The patient undergoing dialysis is subject to more clinical complications, such as irregularities in blood pressure, severe anemia, changes in the metabolism of calcium and phosphorus and malnutrition - which, in its turn, impairs the perception of physical and mental wellbeing ${ }^{(23)}$. The $\mathrm{KTx}$, on the contrary, as it is more similar to the normal functioning of the kidneys, contributes to a health scenario which is more favorable and of greater vitality. In comparison with those remaining in dialysis, the transplant recipients present higher scores for quality of life on the SF-36 instrument ${ }^{(24)}$. More appropriate clinical parameters lead to a more positive perception of oneself, promoting adaptation to the disease and coping with the demands posed by the treatment.

Even in the light of the numerous gains made possible by the KTx, one cannot exclude the chronic condition of kidney disease, as the transplant recipient continues to be a chronically-ill patient subject to 
continuous treatment(13). Various challenges were perceived by the study participants, and are similar to those observed in international studies ${ }^{(7-12,14)}$.

In spite of the advances made in immunosuppressive medication and techniques of clinical treatment, the fear related to the loss of the graft was reported as one of the principal stressors following KTx. This same result was found by other researchers ${ }^{(7-9,11,13-14)}$, in which the fear of rejection and/or uncertainty about the future, related to health, appear among the greatest concerns of the kidney transplant recipient. Those patients who had aversive memories regarding the period of dialysis reported greater fear of losing the graft and having to once more coexist with the hemodialysis machine and all the associated complications.

The limitation of activities can also be associated with the intensity of the feeling of fear. Avoidance behavior, or the persistence of thoughts of selfcontrol, important stressors described in this study, contribute to the development of scenarios of anxiety, negatively influencing quality of $\operatorname{life}^{(8)}$. Thus, one can perceive a contradictory feeling between the stressor of "limitation" and the gains of "return to activities" and "independence/freedom". As a result, positive changes brought by the KTx may not be experienced by some patients, depending on their beliefs and on how they cope with the challenges.

Issues linked to medication were cited as causing much tension, principally when the side effects of the immunosuppressive medication are present. The medication regimen was also considered a strong stressor in other studies ${ }^{(7,13)}$. Living with the side effect symptoms can lead to a worse perception of physical and mental health, negatively interfering with the return to activities and general well-being(25). In one study on stress generated by the side effects of the immunosuppressive medication, in 157 patients who had received KTx fewer than seven years previously, among the main consequences related to the medication were emotional alterations, such as fear and anxiety ${ }^{(9)}$. In one systematic review of qualitative studies on the perspectives of the use of the medication, the properties of the medication - such as texture, size, odor and side effects - were considered as obstacles for the kidney transplant recipients ${ }^{(15)}$.

Other factors described as challenges by the participants were linked to the treatment and to social roles. One does not return to the lifestyle enjoyed prior to $\mathrm{CKD}^{(7)}$ and the social barriers ${ }^{(12)}$ are not eliminated through the procedure. Although it constitutes the therapy which is closest to normal life, KTx does not represent a cure for CKD, and requires the transplant recipient to undertake a routine of continuous care for their health and to live with possible stigma present in interpersonal relationships; these, therefore, become obstacles which make it difficult for the transplant recipient to enter specific social/labor tasks, transforming them into sources of stress.

This study presented some limitations. Firstly: the predominance in the sample of transplant recipients who received tissue from live donors. Although, at the time of writing, the majority of Brazilian transplant recipients receive a kidney from a live donor, it is suggested that in future studies a higher percentage of transplant recipients should be included who received a kidney from cadaver donors, as in this type of donation there are different questions, which are not faced or shared when the transplant occurs between living people - such as guilt for the death of the donor, and the incorporation of his psychological characteristics ${ }^{(10)}$. Secondly: the inclusion of only patients with more than one year since transplantation, excluding those who are under assessment, or those who are on "active" status, but who are waiting for an organ to be donated. A longitudinal study, including the different periods which involve kidney transplantation (pre-, peri- and post-transplant) could better clarify the issues and difficulties perceived by these patients throughout the entire process.

\section{Final considerations}

Understanding the factors associated with health behaviors has been one of the major challenges for researchers interested in the advance in the treatment of chronic diseases. As a result, the present study raised questions which must be discussed and included in the context of KTx: the experiences of the transplant recipient regarding her treatment, and the implication of these in her life. These findings, in a Brazilian population, match those found in the international literature, leading to the conclusion of the existence of questions which are intrinsic to $\mathrm{KTx}$, regardless of the cultural and social context. However, the difference - regarding the impact of these issues, both in the routine of the transplant recipient and in her adaptation to the treatment - is influenced by various factors, such as mental health and the coping style.

The availability of various personal resources cognitive, psychological and social - is also considered an important tool, contributing positively in the transplant 
recipient's process of adaptation. Among these resources, the support of the health team is included, in relation to both the pedagogical and therapeutic functions. In this way, the recognition of the principal challenges to be overcome by the patient can help the health professionals to provide a more humanized and holistic care. Such conduct contributes to the construction of an environment which is favorable to the development of healthy behaviors, including adherence to the treatment, an important factor for the results of the KTx and for quality of life.

\section{References}

1. Zhang $\mathrm{QL}$, Rothenbacher D. Prevalence of chronic kidney disease in population-based studies: systematic review. BMC Public Health. 2008;8:117-29.

2. Sociedade Brasileira de Nefrologia [Internet]. 2014. Censo de diálise SBN 2012. [acesso 13 jan 2014]. Disponível em http://sbn.org.br/pdf/censo_2013_ publico_leigo.pdf

3. Neipp $\mathbf{M}$, Jackobs $\mathrm{S}$, Klempnauer J. Renal transplantation today. Langenbecks Arch Surg. 2009;394(1):1-16.

4. Ostrowiski M, Wesolowski T, Makar D, Bohatyrewicz R. Changes in patients quality of life after renal transplantation. Transplant Proc. 2000;32(6):1371-4.

5. Denhaerynck K, Dobbels F, Cleemput I, Desmyttere A, Schäfer-Keller $P$, Schaub $S$, et al. Prevalence, consequences, and determinants of nonadherence in adult renal transplant patients: a literature review. Transpl Int. 2005;18(10):1121-33.

6. Marsicano EO, Fernandes NS, Colugnati F, Grincenkov FRS, Fernandes NMS, De Geest S, et al. Transcultural adaptation and initial validation of Brazilian-Portuguese version of the Basel assessment of adherence to immunosuppressive medication scale (BAASIS) in kidney transplant. BMC Nephrol. 2013;14:2-8.

7. Fallon M, Gould D, Wainwrigth SP. Stress and quality of life in the renal transplant patient: a preliminary investigation. J Adv Nurs. 1997;25(3):562-70.

8. Chen KH, Weng, LC, Lee S. Stress and stressrelated factors of patients after renal transplantation in Taiwan: a cross-sectional study. J Clin Nurs. 2010;19:2539-47.

9. Rosenberger J, Geckova AM, Dijk JP, Roland R, Heuvel WJA, Groothoff JW. Factors modifying stress from adverse effects of immunosuppressive medication in kidney transplant recipients. Clin Transplant. 2005;19(1):70-6.
10. Kong ILL, Molassiotis A. Quality of life, coping and concerns in Chinese patients after renal transplantation. Int J Nurs Stud. 1999;36(4):313-22.

11. Sutton TD, Murphy SP. Stressors and patterns of coping in renal transplant patients. Nurs Res. 1989;38(1):46-9.

12. Orr A, Willis $S$, Holmes $M$, Britton $P$, Orr D. Living with a kidney transplant: a qualitative investigation of quality of life. J Health Psychol. 2007;12(4):653-62.

13. Hayward MB, Kish JP, Frey GM, Kirehner JM, Carr LS, Wolfe CM. An instrument to identify stressors in renal transplant recipients. ANNA J. 1989;16(2):81-5.

14. White M, Starr AJ, Ketefian S, Voepel-Lewis T. Stress, coping, and quality of life in adult kidney transplant recipients. ANNA J. 1990;17(6):421-4.

15. Tong A, Howell M, Wong G, Webster AC, Howard K, Craig JC. The perspectives of kidney transplant recipients on medicine taking: a systematic review of qualitative studies. Nephrol Dial Transplant. 2011;26:344-54.

16. Freitas MTA. A abordagem sócio histórica como orientadora da pesquisa qualitativa. Cad Pesqui. 2002;(116):21-39.

17. Mason M. Sample size and saturation in PHD studies using qualitative interviews. Forum: Qual Soc Res. [Internet] 2010 [acesso 11 jan 2014];11(3). Disponível em: http://www.qualitative-research.net/index.php/ fqs/article/view/1428/3028

18. Lentine $K L$, Gheorghian A, Axelrod D, Kalsekar A, $L$ 'italien G, Schnitzler MA. The implications of acute rejection for allograft survival in contemporary U.S. kidney transplantation. Transplantation. 2012;94(4):369-76.

19. Lefevre F, Lefevre AMC. Discourse of the collective subject: social representations and communication interventions. Text Contexto Enferm. 2014;23(2):502-7. 20. Pope C, Mays N. Métodos qualitativos na pesquisa em saúde. In: Pope $\mathrm{C}$, Mays $\mathrm{N}$, organizadores. In: Pesquisa qualitativa na atenção à saúde. Porto Alegre: Artmed; 2009. p. 11-22.

21. Kaltsouda A, Skapinakis $P$, Damigos D, Ikonomou M, Kalaitzidis R, Mavreas $V$, et al. Defensive coping and health-related quality of life in chronic kidney disease: a cross-sectional study. BMC Nephrol. 2011;12:12-28.

22. Martins MRI, Cesarino CB. Quality of life in chronic kidney failure patients receiving hemodialysis treatment. Rev. Latino-Am. Enfermagem. 2005;13(5):670-6.

23. Bastos MG, Carmo WB, Abrita RR, Almeida EC, Mafra $D$, Costa DMN, et al. Doença Renal Crônica: problemas e soluções. J Bras Nefrol. 2004;26(4):202-15.

24. Ortiz F, Aronen P, Koskinen PK, Malmstrom RK, Finne $\mathrm{P}$, Honkanen EO, et al. Health-related quality of life after 
kidney transplantation: who benefits the most? Transpl Int. 2014; 27(11):1143-51.

25. Liu H, Feurer ID, Dwyer K, Shaffer D, Pinson CW. Effects of clinical factors on psychosocial variables in renal transplant recipients. J Adv Nurs. 2009;65(12):258596. 